BMJ Open

Diabetes

Research

\& Care

\section{Exercise training improves adipose tissue metabolism and vasculature regardless of baseline glucose tolerance and sex}

To cite: Honkala SM, Motiani P, Kivelä R, et al. Exercise training improves adipose tissue metabolism and vasculature regardless of baseline glucose tolerance and sex. BMJ Open Diab Res Care 2020;8:e000830. doi:10.1136/ bmjdrc-2019-000830

- Additional material is published online only. To view please visit the journal online (http://dx.doi.org/10.1136/ bmjdrc-2019-000830).

SMH and PM contributed equally.

This study has been previously presented at the ADA 77th Scientific Sessions (2017, USA) and European College of Sport Science Congress (2017, Germany).

Received 15 August 2019 Revised 8 May 2020 Accepted 10 June 2020

\section{Check for updates}

(c) Author(s) (or their employer(s)) 2020. Re-use permitted under CC BY-NC. No commercial re-use. See rights and permissions. Published by BMJ.

For numbered affiliations see end of article.

Correspondence to Dr Jarna Christina Hannukainen; jarna.hannukainen@tyks.fi

\section{ABSTRACT}

Introduction We investigated the effects of a supervised progressive sprint interval training (SIT) and moderateintensity continuous training (MICT) on adipocyte morphology and adipose tissue metabolism and function; we also tested whether the responses were similar regardless of baseline glucose tolerance and sex.

Research design and methods 26 insulin-resistant (IR) and 28 healthy participants were randomized into 2-week-long SIT (4-6×30s at maximum effort) and MICT (40-60 min at $60 \%$ of maximal aerobic capacity $\left(\mathrm{VO}_{2 \text { peak }}\right)$ ). Insulin-stimulated glucose uptake and fasting-free fatty acid uptake in visceral adipose tissue (VAT), abdominal and femoral subcutaneous adipose tissues (SATs) were quantified with positron emission tomography. Abdominal SAT biopsies were collected to determine adipocyte morphology, gene expression markers of lipolysis, glucose and lipid metabolism and inflammation. Results Training increased glucose uptake in VAT $(p<0.001)$ and femoral SAT $(p<0.001)$ and decreased fatty acid uptake in VAT $(p=0.01)$ irrespective of baseline glucose tolerance and sex. In IR participants, training increased adipose tissue vasculature and decreased CD36 and ANGPTL4 gene expression in abdominal SAT. SIT was superior in increasing $\mathrm{VO}_{2 \text { peak }}$ and VAT glucose uptake in the IR group, whereas MICT reduced VAT fatty acid uptake more than SIT.

Conclusions Short-term training improves adipose tissue metabolism both in healthy and IR participants independently of the sex. Adipose tissue angiogenesis and gene expression was only significantly affected in IR participants.

\section{INTRODUCTION}

White adipose tissue has long been recognized as the main site for the storage of excess energy delivered from food. Adipose tissue is also an endocrine organ, which regulates glucose and lipid metabolism and secretes a large number of hormones and cytokines. ${ }^{1}$ In obesity and insulin resistance (IR), the metabolism of adipose tissue deteriorates and this is indicated by adipocyte hypertrophy and hyperplasia, macrophage infiltration,

\section{Significance of this study}

What is already known about this subject?

- Adipose tissue metabolism and vasculature is impaired and inflammation increased in type 2 diabetes and obesity. Exercise training has beneficial effects on adipose tissue, but little is known about the effect on glucose and free fatty acid (FFA) metabolism.

What are the new findings?

- Already short-term training improves adipose tissue glucose and fatty acid metabolism especially in visceral adipose tissue despite the baseline glucose tolerance and sex. This study proposes that SIT improves visceral adipose tissue insulin-stimulated glucose uptake more efficiently than MICT, whereas MICT is preferable for visceral adipose tissue FFA uptake.

- After 2 weeks of exercise training, improvements could already be seen in glucose and fatty acid metabolism especially in visceral adipose tissue despite the baseline glucose tolerance and sex.

- This study proposes that sprint interval training (SIT) improves visceral adipose tissue insulin-stimulated glucose uptake more efficiently than moderateintensity continuous training (MICT), whereas MICT is preferable for improvements in visceral adipose tissue FFA uptake.

- Training decreases adipose tissue FFA uptake and the expression of FATB4, CD36 and ANGPTL4 mRNA and increases adipose tissue vascularization in insulin-resistant participants.

How might these results change the focus of research or clinical practice?

- Connections between adipose tissue and other organs should be studied in more detail. This study also strengthens the potential of exercise training in the prevention of type 2 diabetes.

impaired insulin signaling and IR. ${ }^{12}$ Impaired adipose tissue metabolism leads to the release of inflammatory adipokines and large 
amounts of free fatty acids (FFAs) resulting in the accumulation of ectopic fat and lipotoxicity in non-adipose tissues, such as muscle, liver and pancreas. ${ }^{13}$

Previous animal and human studies have shown that regular exercise training has beneficial effects on adipose tissue. Regular exercise training has been shown, both in subcutaneous adipose tissue (SAT) and visceral adipose tissue (VAT), to reduce adipose tissue mass, ${ }^{45}$ adipocyte hypertrophy, adipose tissue inflammation ${ }^{6}$ and increase mitochondrial function and biogenesis ${ }^{7}$ in humans and rodents. A recent study showed that exercise training influences (increase/decrease) global expression of inflammation-related factors especially in abdominal SAT especially in dysglycemic men. ${ }^{6}$ Emerging evidence from preclinical studies suggest that training-induced effects on adipose tissues are tissue specific. ${ }^{8-10}$ For example, VAT has shown to be more responsive to exercise training due to its higher level of adrenergic activation. ${ }^{7}$ In addition, our previous clinical studies using positron emission tomography (PET) have shown that VAT is metabolically more active than SAT with both a higher glucose uptake ${ }^{11}$ and fatty acid uptake. ${ }^{12}$ However, studies comparing exercise training-driven adaptions to SAT and VAT metabolism in humans are more limited.

It is well known that exercise training leads to a decrease in plasma insulin levels and circulating catecholamines and seems to lead to increase in lipolysis in relation to exercise intensity. ${ }^{71314}$ However, during high-intensity training, it has been suggested that the reduction in adipose tissue blood flow leads to a decrease in adipose tissue FFA release. ${ }^{15}$ Sprint interval training (SIT) has been the focus of research as a time-saving training method and it has been suggested to be superior compared with moderate-intensity continuous training (MICT) in improving whole-body glucose metabolism and maximal aerobic capacity $\left(\mathrm{VO}_{\text {2peak }}\right) .1617$ To our knowledge, no previous studies have investigated whether SIT or MICT is preferable in improving the depotspecific adipose tissue metabolism in insulin-resistant (IR) participants.

The aim of the present study was to investigate the effects of 2 weeks of supervised, progressive exercise training on VAT and SAT glucose as well as fatty acid metabolism in healthy participants and participants with IR. Furthermore, using abdominal SAT biopsies, we were able to determine the training-induced effects on adipocyte cell size, adipose tissue vascularization and adipose tissue gene expression markers related to lipolysis, inflammation, adipogenesis, and glucose and FFA transport. Currently it is unclear whether the training responses on adipose tissue metabolism are similar between healthy and IR participants, and whether SIT is superior to MICT. ${ }^{1819}$ The outcome data were also compared between IR men and women as previous studies have shown sex differences in adipose tissue metabolism. ${ }^{20}$ Thus, the present study examined in middle-aged, sedentary participants whether training responses are similar in different adipose tissues:

1. Between healthy and IR participants?
2. After SIT compared with MICT in IR participants?

3. Between women and men in IR participants?

We hypothesized that already 2 weeks of exercise training would induce beneficial changes in adipose tissue glucose and fatty acid metabolism both in healthy and IR participants and these changes would be associated with reduced adipocyte cell size and improved gene expression profile. We also hypothesized that these improvements would be seen both after SIT and MICT regardless of the sex.

\section{RESEARCH DESIGN AND METHODS \\ Ethics}

The study was part of a larger clinical trial (NCT01344928) entitled "The effects of short-term high-intensity interval training on tissue glucose and fat metabolism in healthy participants and in patients with type 2 diabetes." The primary objective of the larger trial was to study the effects of exercise training on skeletal muscle and the outcomes of the present study are explorative. The results related to whole-body insulin sensitivity (M-value), aerobic fitness and basic characteristics in this manuscript have already been published. ${ }^{21-24}$ The main parameters of the present study, adipose tissue metabolism, cell size and gene expression have not been published before either in healthy or in IR subjects. The study was performed at the Turku PET Centre, University of Turku and Turku University Hospital (Turku, Finland) and the Paavo Nurmi Centre (Turku, Finland) between March 2011 and September 2015.

\section{Participants}

Middle-aged, physically inactive, healthy men participants $(n=28)$ and woman and men participants with IR $(n=26)$ were recruited for the study via newspaper advertisements, personal contacts, and electronic and traditional bulletin boards. The inclusion criteria for the healthy participants were men sex, age $40-55$ years, body mass index (BMI) $18.5-30 \mathrm{~kg} / \mathrm{m}^{2}, \mathrm{VO}_{2 \text { peak }}<40 \mathrm{~mL} /$ $\mathrm{kg} / \mathrm{min}$ and normal glycemic control. ${ }^{25}$ The allowed physical activity was limited to twice a week or less. A candidate was excluded if he or she had a condition which could potentially endanger their health during the study or interfere with the interpretation of the results as previously explained in detail. ${ }^{21} 2627$ For the IR participants, the inclusion criteria were the same as for the healthy participants except for BMI $18.5-35 \mathrm{~kg}$ / $\mathrm{m}^{2}$ and an impaired glucose tolerance (IGT) according to the criteria of the American Diabetes Association (ADA),$^{25}$ an glycated hemoglobin (HbA1c) of less than $7.5 \%$ and no insulin treatment in the cases of type 2 diabetes.

Based on the oral glucose tolerance tests (OGTTs), all 26 subjects met the criteria of IR set by $\mathrm{ADA}^{25}$ and had an HbA1c less than $7.5 \%$. At the time of screening, four participants were newly diagnosed with type 2 diabetes and had no previous medication. For the other 11 participants 


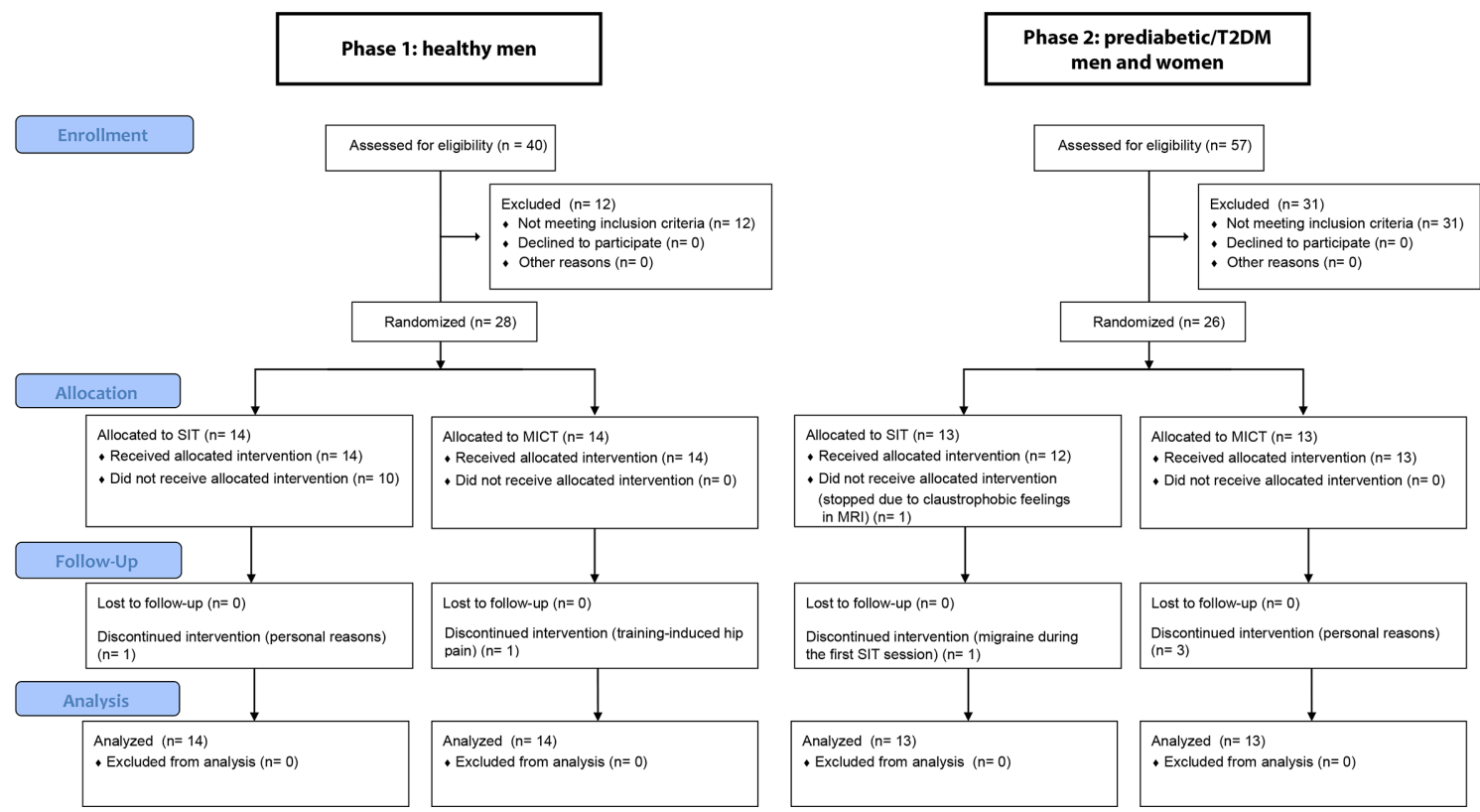

Figure 1 Participant flow diagram. The analyses were carried out using the intention-to-treat principle and hence included all the randomized participants. MICT, moderate-intensity continuous training; SIT, sprint interval training; T2DM, type 2 diabetes mellitus.

with type 2 diabetes, the median diabetes duration was 4.2 years and they were treated by oral hypoglycemic agents (11 with metformin, 5 with sitagliptin and 1 with glimepiride). Antidiabetic medication was withheld for 48 hours and the participants were asked to avoid any exhausting exercise 48 hours prior to the measurements. All participants were asked not to change their habitual dietary intake during the study period. There was a total of seven dropouts in the study (figure 1).

\section{Study design}

The physical examination, OGTT, $\mathrm{VO}_{2 \max }$ test, MRI, hyperinsulinemic clamp and PET with $14(\mathrm{R}, \mathrm{S})-[18 \mathrm{~F}]$ fluoro-6-thia-heptadecanoic acid (FTHA) and 2-[18F] fluoro-2-deoxy-D-glucose (FDG) tracers were performed before and after the training intervention as described in figure 2. Randomization either into the SIT or MICT group was done using a 1:1 allocation ratio and was performed separately for the healthy and prediabetic or type 2 diabetic participants with random permuted blocks, and this has been previously described in detail. ${ }^{21} 2628$ Power calculations were calculated based on the main outcomes of the whole trial (muscle glucose uptake) and have been described previously. ${ }^{22} 29$ No sample size calculation were specifically performed on the outcome measurements of the present study.

\section{Exercise intervention}

Participants participated in a 2-week supervised, progressive training intervention, which included six training sessions of either SIT or MICT. The duration of the intervention was based on previous studies showing improvements in aerobic fitness and insulin sensitivity after only six training sessions. ${ }^{16}{ }^{17}$ Each session was performed in laboratory conditions at the Turku PET Centre under the supervision of a member of the study group.

Each MICT session consisted of 40-60 min of cycling at a moderate intensity, which was determined as $60 \%$ of the measured $\mathrm{VO}_{2 \text { peak }}$ workload monitored by corresponding heart rate (Tunturi E85; Tunturi Fitness, Almere, The Netherlands) based on previous MICT protocols. The duration of the MICT increased progressively starting with $40 \mathrm{~min}$ and increasing by 10 min every other session up to $60 \mathrm{~min}$. SIT sessions consisted of $4-6 \times 30 \mathrm{~s}$ of allout cycling bouts (Monark Ergomedic 894E; MONARK, Vansbro, Sweden), with a 4 min recovery between each bout. The number of bouts increased progressively

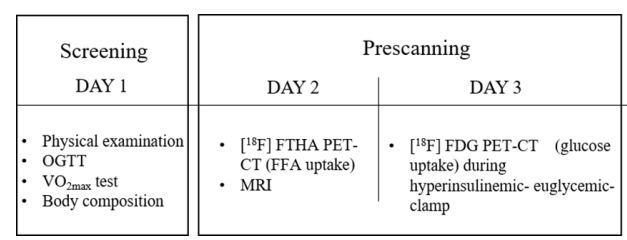

\begin{tabular}{|c|c|}
\hline \multicolumn{2}{|c|}{ Intervention } \\
\hline $\begin{array}{l}\quad \text { SIT } \\
4-6 \text { of } 30 \text { seconds } \\
\text { all-out cycling bouts OR } \\
\text { (Wingate's test) }\end{array}$ & $\begin{array}{c}\text { MICT } \\
40-60 \text { minutes of } \\
\text { cycling at an intensity } \\
\text { of } 60 \% \text { of } \mathrm{VO}_{2 \text { peak }}\end{array}$ \\
\hline
\end{tabular}

\begin{tabular}{|c|c|c|}
\hline \multicolumn{3}{|c|}{ Postscanning } \\
\hline POST $48 \mathrm{H}$ & POST $72 \mathrm{H}$ & POST 96H \\
\hline $\begin{array}{l}\text { - }{ }^{[18 \mathrm{~F}]} \text { FTHA-PET- } \\
\text { CT } \\
\text { - } \\
\text { MRI }\end{array}$ & $\begin{array}{l}\left.-{ }^{18} \mathrm{~F}\right] \text { FDG-PET- } \\
\mathrm{CT}, \\
\text { hyperinsulinemic- } \\
\text { euglycemic- } \\
\text { clamp }\end{array}$ & $\begin{array}{ll}\cdot & \mathrm{VO}_{2 \max } \text { test } \\
\text { - OGTT } \\
\text { Body } \\
\text { composition }\end{array}$ \\
\hline
\end{tabular}

Figure 2 The study design. [18F] FDG, 2-[18F]fluoro-2-deoxy-D-glucose; [18F] FTHA, 14(R,S)-[18F]fluoro-6-thiaheptadecanoic acid; FFA, free fatty acid; MICT, moderate-intensity continuous training; OGTT, oral glucose tolerance test; PET, positron emission tomography; SIT, sprint interval training; $\mathrm{VO}_{2 \max }$, maximal aerobic capacity. 
starting with four bouts and increasing by one every other session up to six bouts per session. The training load was individually determined (for healthy participants $7.5 \%$ of whole-body weight in kilogram, for IR participants $10 \%$ of lean body mass in kilogram).

\section{Magnetic resonance imaging}

VAT and abdominal SAT depot masses were measured with MRI (Philips Gyroscan Intera 1.5 T CV Nova Dual scanner, Philips Medical Systems). Whole-body (from head to knee) axial T1-weighted dual-fast field echo images (TE 2.3 and $4.7 \mathrm{~ms}$, TR $120 \mathrm{~ms}$, slice thickness $10 \mathrm{~mm}$ without gap) were obtained and analyzed using sliceOmatic software V.4.3 (http://www.tomovision. $\mathrm{com} /$ products/sliceomatic.html). To obtain the tissue mass, the pixel surface area was multiplied by slice thickness and density of adipose tissue $0.9196 \mathrm{~kg} / \mathrm{L}$. Unfortunately, we were not able to measure femoral SAT mass as the MRI was not performed on the whole femoral region.

\section{Positron emission tomography}

Participants underwent four PET sessions: one $\left[{ }^{18} \mathrm{~F}\right]$ FTHA PET and one $\left[{ }^{18}\right.$ F]FDG PET before and after the training intervention. An euglycemic-hyperinsulinemic clamp was performed during $\left[{ }^{18} \mathrm{~F}\right] \mathrm{FDG}$ PET scanning day after a 10-hour fast based on the original protocol by Defronzo et al..$^{30}$ During the first $4 \mathrm{~min}$, a primed-constant insulin (Actrapid, $100 \mathrm{U} / \mathrm{mL}$; Novo Nordisk, Bagsvaerd, Denmark) infusion was started at a rate of $120 \mathrm{mU} / \mathrm{m}^{2}$ / min of body surface area. After the first $4 \mathrm{~min}$, the infusion rate was decreased to $80 \mathrm{mU} / \mathrm{m}^{2} / \mathrm{min}$ for $3 \mathrm{~min}$, and then further decreased to $40 \mathrm{mU} / \mathrm{m}^{2} / \mathrm{min}$ for the rest of the clamp. Normoglycemia was adjusted with $20 \%$ glucose infusion. Plasma glucose concentration was determined every 5-10 min from arterialized venous blood, and insulin and FFA concentrations were determined every 30 and $60 \mathrm{~min}$, respectively. The M-value was calculated from the glucose infusion rate and the measured glucose values collected when the participants had reached a steady state during the PET scan. The participants were positioned supine in a PET scanner (GE Discovery ST System, Milwaukee, Wisconsin, USA). To measure the plasma radioactivity for tracer input function, arterialized venous blood samples were collected repeatedly during $\left[{ }^{18}\right.$ F $]$ FTHA and $\left[{ }^{18}\right.$ F $]$ FDG scanning. Plasma radioactivity was measured with an automatic gamma counter (Wizard 1480 3"; Wallac, Turku, Finland).

\section{Regions of interest (ROIs)}

All the imaging data were corrected for dead time, decay and measured photon attenuation, and then reconstructed with scanner software using a 3D-ordered subset expectation maximization (3D-OSEM). Carimas 2.9 software (Turku PET Centre, Turku, Finland) was used to analyze all the acquired PET-CT images. The ROIs were drawn manually on abdominal white SAT, on planes superior to the umbilicus, on VAT at the level of the umbilicus and on femoral subcutaneous tissue at the midregion of the thigh using the CT as an anatomical reference. The rate constant $(\mathrm{Ki})$ for the uptake of radiotracer $\left(\left[{ }^{18} \mathrm{~F}\right]\right.$ FTHA, $\left[{ }^{18} \mathrm{~F}\right] \mathrm{FDG}$ ) into the cells was calculated using tissue time activity curves obtained from the abdominal SAT, VAT and femoral SAT using a fractional uptake method. Regional glucose and FFA uptakes were calculated by multiplying regional specific $\mathrm{K}_{1}$ by corresponding plasma glucose or FFA concentration, respectively. For glucose uptake the products were further divided by a lumped constant value of 1.0 and a tissue density of 0.9136 in adipose tissue. ${ }^{31}$

\section{Adipose tissue biopsy and processing}

Adipose tissue biopsies were performed under local anesthesia after all PET scannings had been performed. Abdominal SAT was biopsied $6-8 \mathrm{~cm}$ laterally from the umbilicus under local anesthesia. For the gene expression analyses, the tissue sample was snap frozen in liquid nitrogen and stored at $-70^{\circ} \mathrm{C}$. For adipocyte cell size analyses tissue sample was fixed overnight in $4 \%$ paraformaldehyde (PFA) and embedded in paraffin for histological sections.

\section{RNA isolation, complementary DNA (cDNA) synthesis and reverse transcriptase PCR}

To isolate RNA from the human abdominal SAT, a piece of the tissue was homogenized in $700 \mu \mathrm{L}$ of TRIsure reagent (Bioline, USA) using the bead-based tissue homogenizer PowerLyzer24 (MO BIO Laboratories, USA). The genomic DNA (gDNA) in the lysate was removed using a gDNA eliminator spin column and the RNA was purified using RNeasy plus micro kit (Qiagen, no: 74034) according to the manufacturer's instructions. RNA was reverse transcribed into cDNA with a high-capacity cDNA reverse transcription kit (Applied Biosystems, no: 4368814), and gene expression was analyzed using a FastStart Universal SYBR green master mix (Sigma-Aldrich, no: 04913914001) kit. The gene expression assay was performed in Bio-Rad C1000 thermal cycler according to the standardized protocol of the quantitative PCR master mix supplier. The quantification cycle $(\mathrm{Cq})$ values of the technical triplicates were collected using Bio-Rad CFX Manager software (v3.1). The data were imported to qBase plus software (Biogazelle, https://www.qbaseplus. com), and the Cq average of each sample were normalized to the housekeeping genes 36B4 and YWHAZ. The mRNA expression level was calculated and presented as fold a change (control=1). The human primer sequences are listed in online supplementary material.

\section{Immunohistochemistry}

Eight-micrometer-thick abdominal SAT sections were deparaffinized, incubated in high $\mathrm{pH}$ antigen retrieval buffer, rinsed with phosphate-buffered saline (PBS) and blocked with DIM buffer (5\% normal donkey serum, $0.2 \%$ bovine serum albumin, $0.3 \%$ Triton $\mathrm{X}-100 \%$ and $0.005 \%$ sodium azide). The sections were incubated overnight at $4^{\circ} \mathrm{C}$ with the following primary antibodies: mouse 
anti-human CD31 (no: M0823; DAKO) and guinea pig anti-human perilipin (no: 20R-PP004; Fiztgerald) to stain vasculature and adipocytes, respectively. The Alexaconjugated 488 and 594 secondary antibodies (Molecular Probes, Invitrogen) were used to detect primary antibody signal. The sections were stained for DAPI, rinsed with PBS, fixed with $1 \%$ PFA dissolved in PBS for 5 min at $4^{\circ} \mathrm{C}$. The stained sections were mounted using VECTASHIELD Hardset Antifade Mounting Medium (H-1400; Vector Laboratories). Images of $40 \times$ were acquired using an Axio imager upright epifluorescence microscope (Carl Zeiss). The images were initially adjusted for threshold and area fraction tool was used to quantify the vasculature area $(\%)$. The adipocyte size was measured using a cell profiler pipeline on a in Cell Profiler image analysis platform (Carpenter Lab, Broad Institute, https://www. cellprofiler.org). ${ }^{32}$

\section{Biomarkers in plasma}

Concentrations of tumor necrosis factor alpha (TNF- $\alpha)$, vascular endothelial growth factor D and A (VEGF-A) and also, C-reactive protein (CRP) were measured by multiplex bead assay analysis (Luminex Performance Assay Multiplex Kit; Procarta Immunoassay Affymetrix, Santa Clara, California, USA) according to the manufacturer's instructions. Samples were analyzed with a LUMINEX 200 using Luminex xPonent software (Luminex, USA).

\section{Other measurements}

Aerobic capacity was determined with a $\mathrm{VO}_{2 \max }$ cycling ergometer test (ergoline $800 \mathrm{~s}$; VIASYS Healthcare, Germany) at the Paavo Nurmi Center (Turku, Finland) about 1 week before the first training session and 96 hours after the last training session. The $\mathrm{VO}_{2 \max }$ test has previously been described in detail by Kiviniemi et al. ${ }^{33}$ Body composition was determined using the bioimpedance method (InBody 720; Mega Electronics, Kuopio, Finland).

\section{Statistical analysis}

The normal distribution of the variables was tested first with the Shapiro-Wilk test and evaluated visually. After the hierarchical mixed linear models, the normal distribution of the studentized residuals was evaluated visually using $Q-Q$ plots. Logarithmic $(\log 10)$ or square root transformations were performed when appropriate to achieve a normal distribution. Statistical analyses were performed using hierarchical mixed linear models with compound symmetry covariance structure. First, the differences between healthy and IR men were studied with the model, which included one within-factor term (time, indicating the overall mean change between baseline and measurement after the intervention, used repeated statement in SAS), one between-factor term (IR; healthy and IR men) and one interaction term (timexIR, indicating whether mean change during the study was different between healthy and IR men). IR women were completely excluded when comparing the effects of exercise in healthy and IR participants to avoid mixing the effects of sex and glucose intolerance. Second, in IR participants, differences between SIT and MICT, including both men and women, were studied using a model that included a within-factor time, a between-factor group (SIT and MICT) and interaction terms (timextraining, whether the mean change was different in the SIT and MICT groups). Third, differences between men and women in IR participants were studied using a model that included a withinfactor group (men and women) and interaction terms (time $\times$ sex, whether mean change was different between men and women). Healthy subjects were excluded from the investigation of exercise regimen (SIT vs MICT) and sex, as we were specifically interested about whether the training responses are different after SIT and MICT in IR population known to have metabolic impairments. In all analyses, time, training, sex and insulin level (healthy vs IR) were handled as fixed effects.

The analyses were carried out using the intention-totreat principle and included all the randomized participants. Missing data points were accounted for by using a restricted maximum likelihood estimation within the linear mixed models. Correlations were calculated using Pearson's correlation (Spearman's rank correlation for non-normally distributed data). The statistical tests were performed as two sided and the level of statistical significance was set at 0.05 . The analyses were performed using an SAS System, V.9.4 for Windows (SAS Institute, Cary, North Carolina, USA).

\section{RESULTS}

\section{Healthy versus insulin-resistant (IR) men}

Of the 26 IR participants, 16 had type 2 diabetes and 10 impaired fasting glucose and/or IGT. In the MICT group, all participants attended all training sessions and in the SIT group 21 participants (12 healthy, 9 IR) attended all six sessions and three participants (1 heathy, 2 IR) attended five sessions. The total training time in the SIT group was on average $14 \pm 1.3 \mathrm{~min}$ as all participants were not able to perform all exercise bouts for the entire $30 \mathrm{~s}$ time. The average number of bouts for heathy was 27.5 and for IR 28.6 when the maximum number of bouts was $30(4+4+5+5+6+6)$. The average power for the MICT group was $127.8 \pm 24.3 \mathrm{~W}$ (healthy $133.2 \pm 17.3 \mathrm{~W}$ and IR 117.7 $\pm 32.6 \mathrm{~W}$ ) and for the SIT group $427.3 \pm 62.3$ W (healthy $407.2 \pm 47.8$ and IR $449.0 \pm 75.9 \mathrm{~W}$ ) The dropouts are not included in these calculations.

The basic characteristics are presented as central tendencies in table 1 and as model-based means in table 2. The estimated mean differences, estimated mean ratios and upper and lower confidence intervals (Cls) for the variables are presented in the online supplementary tables 1 and 2. The IR men had significantly higher body adiposity, circulating lipid values, impaired glucose homeostasis and aerobic fitness as well as a tendency to have higher CRP levels compared with healthy controls 
Table 1 Central tendency and dispersion of the variables in each participant group at the baseline

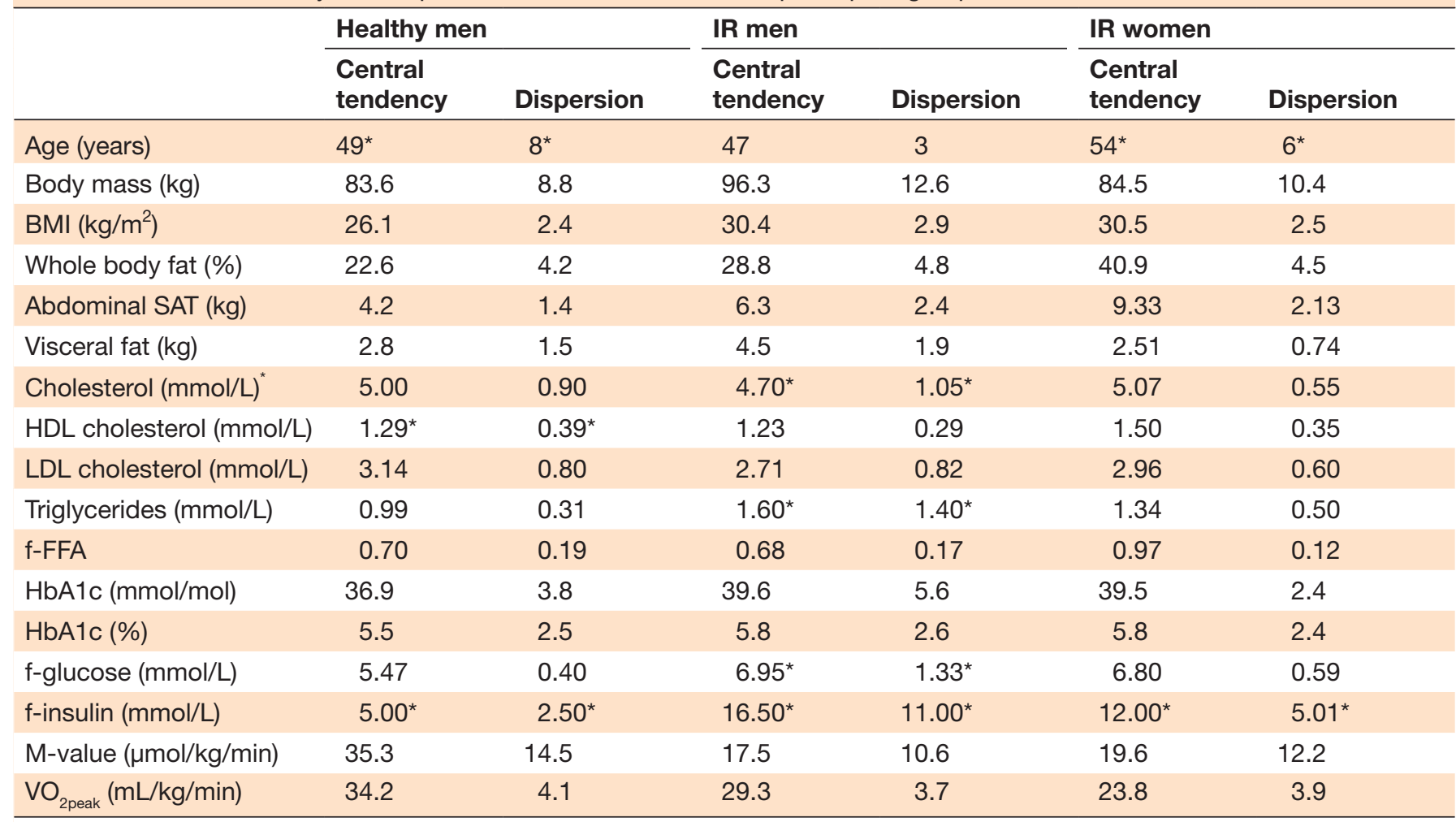

For normally distributed parameters, measure of central tendency is expressed as arithmetic mean and dispersion as SD. For non-normally distributed parameters, measure of central tendency is expressed as median and dispersion as IQR (the difference between 75th and 25th percentiles).

*Non-normally distributed parameters.

BMI, body mass index; f-FFA, fasting free fatty acid; HbA1c, glycated hemoglobin; HDL, high-density lipoprotein; IR, insulin resistance; LDL, low-density lipoprotein; M-value, whole-body insulin sensitivity; SAT, subcutaneous adipose tissue; $\mathrm{VO}_{2 \text { peak}}$, maximal aerobic capacity.

as summarized in table 2 and figure 3 . Notably, the VAT and abdominal SAT masses were higher in IR men than in healthy men (38\% and $36 \%$, respectively). Both interventions were associated with reduced body adiposity and improved cholesterol values and aerobic fitness both in the healthy and the IR men (table 2) but did not have a significant effect on abdominal SAT adipocyte cell size (figure 4C).

At baseline, the IR men had significantly lower glucose uptake $(\mu \mathrm{mol} / \mathrm{min} / 100 \mathrm{~g})$ in their VAT and in their femoral and abdominal SAT than the healthy men (all $\mathrm{p}<0.001$; figure 5 ). These baseline differences were not seen when comparing the glucose uptake for each whole tissue mass in VAT and abdominal SAT (online supplementary figure 1). Glucose uptake in both VAT (time $\mathrm{p}<0.001$; figure 5) and femoral SAT (time $\mathrm{p}<0.001$; figure 5) increased with training, similarly in the healthy and IR men. Only femoral SAT glucose uptake remained lower in the IR men compared with the healthy participants after the intervention.

Before the intervention, the IR participants had lower visceral and abdominal SAT fatty acid uptake levels than the healthy men (both 35\%, $\mathrm{p}<0.001$; figure 6) but we found no difference in femoral SAT fatty acid uptake $(\mathrm{p}=0.3)$ between the groups. Both in healthy and IR men, training decreased fatty acid uptake in VAT (time $\mathrm{p}=0.01$ ) and tended to decrease fatty acid uptake in abdominal and femoral SAT depots (time $\mathrm{p}=0.06$ and time $\mathrm{p}=0.07$, respectively). After training, the fatty acid uptake only remained lower in the abdominal SAT of the IR group when compared with the healthy men.

Of the plasma inflammation and vascularization markers studied, exercise training reduced TNF- $\alpha$ $(p=0.02)$ and VEGF-A $(p=0.02)$ in the whole group with no differences between healthy and IR men (figure 7). We did not observe baseline differences in adipose tissue mRNA expression in genes related to lipolysis, inflammation, adipogenesis and glucose and the FFA transport between IR and healthy participants (figure 7).

\section{SIT versus MICT in IR men and women}

No differences were observed in basic characteristics between the SIT and MICT training groups either at baseline or after the intervention (online supplementary table 3). For the whole group, training was associated with a decrease in VAT mass, high-density lipoprotein, low-density lipoprotein (LDL), total cholesterol, HbA1c concentrations and increase in whole-body insulin sensitivity without any significant differences being found between the two training modes. When studied 
Table 2 Descriptive statistics and results of hierarchical mixed linear models in characteristics of healthy and IR men

\begin{tabular}{|c|c|c|c|c|c|c|c|}
\hline & Healthy men & & IR men & & Baseline & & \\
\hline & Pre & Post & Pre & Post & $P$ value & Time & IR \\
\hline $\mathrm{n}$ & 28 & 26 & 16 & 13 & - & - & - \\
\hline Age (years) & 48 & - & 49 & - & - & - & - \\
\hline Body mass $(\mathrm{kg})$ & 83.6 (79.6 to 87.6$)$ & 83.3 (79.3 to 87.3 ) & 96.3 (91.0 to 101.7 ) & 96.1 (90.8 to 101.5$)$ & $<0.001$ & 0.22 & 0.78 \\
\hline BMI $\left(\mathrm{kg} / \mathrm{m}^{2}\right)$ & 26.1 (25.1 to 27.1$)$ & 26.0 (25.0 to 27.0$)$ & 30.4 (29.1 to 31.8$)$ & 30.4 (29.0 to 31.8$)$ & $<0.001$ & 0.18 & 0.69 \\
\hline $\begin{array}{l}\text { Whole-body fat } \\
(\%)^{*}\end{array}$ & 22.1 (20.5 to 23.9 ) & 21.1 (19.5 to 22.7 ) & 28.4 (25.6 to 31.5$)$ & 27.6 (24.9 to 30.7$)$ & $<0.001$ & $<0.001$ & 0.30 \\
\hline $\begin{array}{l}\text { Abdominal SAT } \\
(\mathrm{kg})\end{array}$ & 4.1 (3.5 to 4.7 ) & 4.0 (3.4 to 4.6$)$ & 6.1 (5.18 to 7.18$)$ & 6.0 (5.1 to 7.1$)$ & $<0.001$ & 0.04 & 0.84 \\
\hline Visceral fat $(\mathrm{kg}) \dagger$ & 2.5 (2.0 to 3.2 ) & 2.4 (1.9 to 3.08 ) & 4.3 (5.4 to 3.4$)$ & 4.1 (3.1 to 5.1$)$ & 0.002 & 0.002 & 0.48 \\
\hline $\begin{array}{l}\text { Cholesterol } \\
(\mathrm{mmol} / \mathrm{L})^{*}\end{array}$ & 4.92 (4.57 to 5.29$)$ & 4.40 (4.08 to 4.74$)$ & 4.71 (4.27 to 5.19$)$ & 4.31 (3.90 to 4.77 ) & 0.44 & $<0.001$ & 0.52 \\
\hline $\begin{array}{l}\text { HDL cholesterol } \\
(\mathrm{mmol} / \mathrm{L})^{*}\end{array}$ & 1.37 (1.25 to 1.50$)$ & 1.27 (1.15 to 1.39$)$ & 1.20 (1.06 to 1.35$)$ & 1.09 (0.96 to 1.23$)$ & 0.08 & $<0.001$ & 0.66 \\
\hline $\begin{array}{l}\text { LDL cholesterol } \\
(\mathrm{mmol} / \mathrm{L})\end{array}$ & 3.14 (2.85 to 3.43$)$ & 2.78 (2.48 to 3.08 ) & 2.73 (2.34 to 3.12 ) & 2.58 (2.18 to 2.98 ) & 0.09 & $<0.001$ & 0.16 \\
\hline $\begin{array}{l}\text { Triglycerides } \\
(\mathrm{mmol} / \mathrm{L})^{*}\end{array}$ & 0.94 (0.81 to 1.11$)$ & 0.83 (0.70 to 0.98$)$ & 1.70 (1.38 to 2.10$)$ & 1.50 (1.19 to 1.90$)$ & $<0.001$ & 0.08 & 0.96 \\
\hline$f-F F A$ & 0.70 (0.62 to 0.77$)$ & 0.62 (0.54 to 0.69$)$ & 0.69 (0.60 to 0.78$)$ & 0.68 (0.59 to 0.78$)$ & 0.86 & 0.04 & 0.11 \\
\hline $\mathrm{HbA1c}(\mathrm{mmol} / \mathrm{L})$ & 36.93 (35.19 to 38.66$)$ & 34.72 (32.94 to 36.50$)$ & 39.64 (37.33 to 41.96$)$ & 37.65 (35.27 to 40.02$)$ & 0.07 & $<0.001$ & 0.81 \\
\hline $\mathrm{HbA1c}(\%)$ & 5.5 (5.4 to 5.7$)$ & 5.3 (5.2 to 5.5$)$ & 5.8 (5.6 to 6.0$)$ & 5.6 (5.5 to 5.8$)$ & 0.07 & 0.001 & 0.8 \\
\hline $\begin{array}{l}\text { f-glucose } \\
(\mathrm{mmol} / \mathrm{L})^{*}\end{array}$ & 5.44 (5.25 to 5.64$)$ & 5.74 (5.52 to 5.96$)$ & 7.20 (6.86 to 7.56$)$ & 7.16 (6.80 to 7.55$)$ & $<0.001$ & 0.15 & 0.80 \\
\hline f-insulin (mmol/L) & 4.70 (3.75 to 5.90$)$ & 5.85 (4.61 to 7.43$)$ & 14.49 (10.72 to 19.57$)$ & 13.58 (9.87 to 18.68$)$ & 0.001 & 0.37 & 0.10 \\
\hline $\begin{array}{l}\text { M-value } \\
(\mu \mathrm{mol} / \mathrm{kg} / \mathrm{min})\end{array}$ & 32.2 (26.6 to 39.0$)$ & 35.5 (29.2 to 43.2$)$ & 14.8 (11.4 to 19.2$)$ & 19.2 (14.7 to 25.19$)$ & $<0.001$ & 0.001 & 0.1 \\
\hline $\begin{array}{l}\mathrm{VO}_{2 \text { peak }} \\
(\mathrm{mL} / \mathrm{kg} / \mathrm{min})\end{array}$ & $34.2(32.7$ to 35.7$)$ & 35.7 (34.2 to 35.7$)$ & 29.4 (27.3 to 31.5$)$ & 30.0 (27.9 to 32.1$)$ & $<0.001$ & 0.003 & 0.14 \\
\hline
\end{tabular}

The p-value for "baseline" describes the baseline differences between the healthy $(n=28)$ and IR $(n=16)$ groups. "Time" shows all healthy and IR men after training. "Time*IR" demonstrates whether there is an interaction between the pre-post change and health status. All the data are presented as model-based means $(95 \% \mathrm{Cl})$. The values are model-based means and Cls translated into the original unit.

Bold values are statistically significant.

*Logarithmic transformation has been done to the variables to achieve the normal distribution.

†Square transformation to the variables to achieve the normal distribution.

BMI, body mass index; f-FFA, fasting free fatty acid; HbA1c, glycated hemoglobin; HDL, high-density lipoprotein; IR, insulin resistance; LDL, lowdensity lipoprotein; M-value, whole-body insulin sensitivity; SAT, subcutaneous adipose tissue; $\mathrm{VO}_{2 \text { peak }}$, maximal aerobic capacity.

according to the exercise mode, only SIT was associated with an increase in the $\mathrm{VO}_{2 \text { peak }}(\mathrm{SIT}+5 \%$ vs MICT $0 \%$, time*training $\mathrm{p}=0.047$ ).

Femoral SAT glucose uptake improved with both SIT and MICT (25\% and 20\%, respectively, time $\mathrm{p}=0.004$ ). However, in the VAT the training response was different between the two training modes with only SIT increasing VAT glucose uptake $(30 \%$ vs $4 \%$, time*training, $\mathrm{p}=0.03$ ) and only MICT was associated with reduced VAT fatty acid uptake $(-30 \%$ vs $3 \%, \mathrm{p}=0.01$ ) (figure 5). Interestingly, the differential responses between the two training modes were still present when the VAT glucose uptake and fatty acid uptake were calculated per tissue depot (time*training, $\mathrm{p}=0.03$ and $\mathrm{p}=0.007$, respectively) (online supplementary figures 1 and 2). Additional descriptive statistics and results linear mixed model with repeated measures for characteristics of SIT and MICT training groups in all healthy and IR subjects, including both men and women, are presented in online supplementary table 4 .

Of the studied genes, we found a significant decrease in CD36 and ANGPTL4 ( $\mathrm{p}=0.042$ and $\mathrm{p}=0.047$, respectively) after both training modes (figure 7 ). In addition, we saw an increase in adipose tissue vascularization after both training modes (figure 3B).

\section{IR men versus IR women}

IR women differed markedly from IR men, being older and having significantly higher whole-body fat content, abdominal SAT mass and plasma FFA concentration. However, they had significantly lower VAT mass when compared with IR men (online supplementary table 5).

At baseline, VAT glucose uptake and fatty acid uptake (19\%, p=0.04 and 37\%, $\mathrm{p}=0.002$, respectively) and femoral SAT fatty acid uptake $(18 \%, \mathrm{p}=0.02)$ were significantly higher in women compared with men (figure 6), 

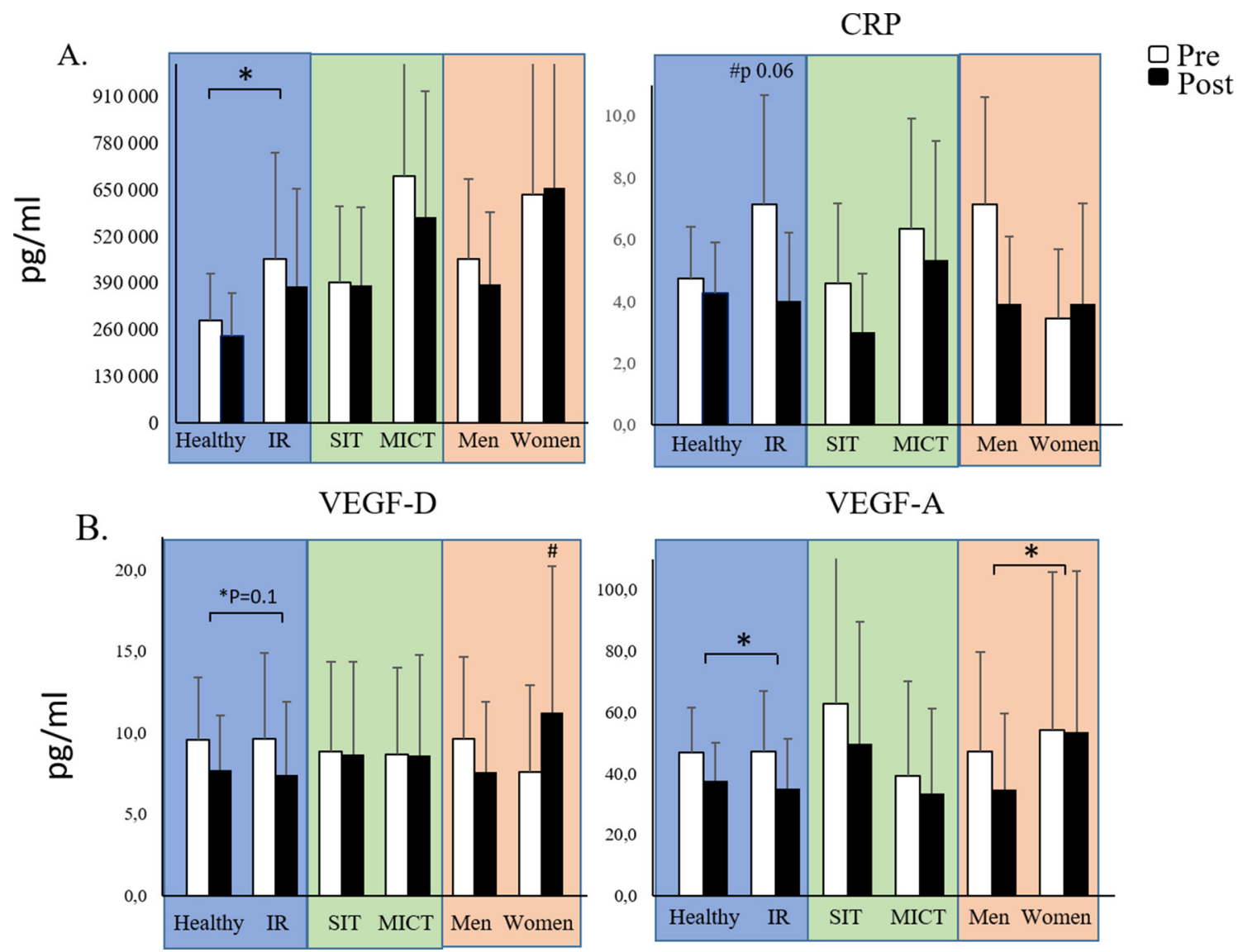

Figure 3 Levels of different markers of $(A)$ inflammation and (B) vascularization in plasma. Markers are visualized in three different comparisons: healthy versus insulin-resistant (IR) men, sprint interval training (SIT) versus moderate-intensity continuous training (MICT) in IR participants and men versus women in IR participants. All data are expressed as means and 95\% Cls. \#p<0.05: difference at baseline. ${ }^{*} p<0.05$ : the effect of exercise training over time in the whole group or a subgroup. Model-based means together with $95 \% \mathrm{Cls}$ are presented. CRP, C reactive protein; TNF- $\alpha$, tumor necrosis factor alpha; VEGF, vascular endothelial growth factor.

but no significant baseline difference was found in abdominal SAT glucose uptake (figure 5). Training was associated with an increase in VAT glucose uptake both in men and women $(21 \%$ and $8 \%$, respectively, time $\mathrm{p}=0.04)$ and decreased VAT fatty acid uptake $(-15 \%$ and $-17 \%$, respectively, time $\mathrm{p}=0.03$ ) with no difference between the sexes. However, only men showed improvement in femoral SAT glucose uptake after exercise training (men $37 \%$ vs women $7 \%$, time*sex $\mathrm{p}=0.02$ ).

\section{DISCUSSION}

The aim of the study was to investigate the effects of a 2-week-long supervised, progressive exercise training on adipose tissue metabolism and morphology. The study demonstrates that short-term exercise training was associated with an increase in insulin-stimulated VAT and femoral SAT glucose uptake and reduction in fasting VAT fatty acid uptake both in healthy participants and participants with IR. Interestingly, only SIT was associated with increased VAT glucose uptake, whereas only MICT decreased VAT fatty acid uptake in participants with IR. In addition, we observed an increase in adipose tissue vasculature and a decrease in abdominal SAT CD36 and ANGPTL4 mRNA expression in IR participants after both training modes. As expected, ${ }^{20}$ we found that women have metabolically more active adipose tissue than men with both higher glucose uptake and fatty acid uptake in VAT and femoral SAT.

\section{Healthy versus IR (men)}

In the present study, glucose uptake $(\mu \mathrm{mol} / \mathrm{min} / 100 \mathrm{~g})$ was $29 \%$ lower in VAT, $32 \%$ lower in abdominal SAT and $50 \%$ lower in femoral SAT in IR participants compared with healthy participants. However, when calculated per tissue depot, glucose uptake in these adipose tissues was similar between healthy and IR participants due to the significantly greater masses of these fat depots in the IR group as also shown previously. ${ }^{11}$

Exercise training induced significant improvements in VAT and femoral SAT glucose uptake both in healthy $(5 \%$ and $18 \%)$ and IR participants $(21 \%$ and $36 \%$ ), respectively. Studies investigating the effects of training on adipose tissue insulin-stimulated glucose uptake in vivo in humans are scarce. Opposite to our findings, Reichkendler et al found a decrease in the 
A

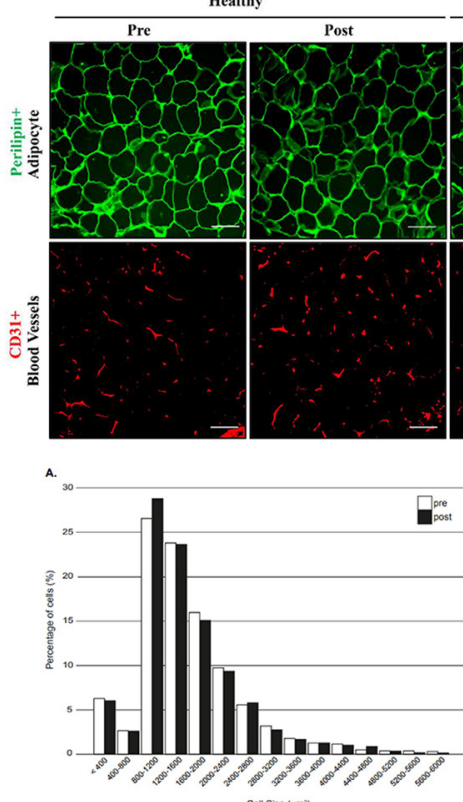

Diabetic

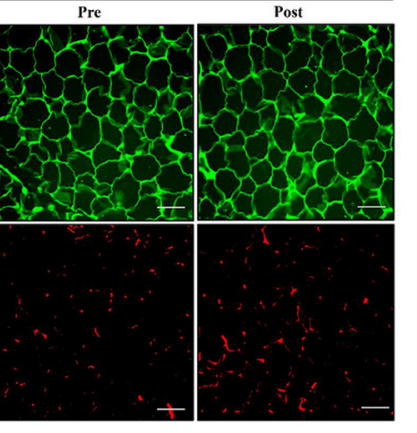

B.

B
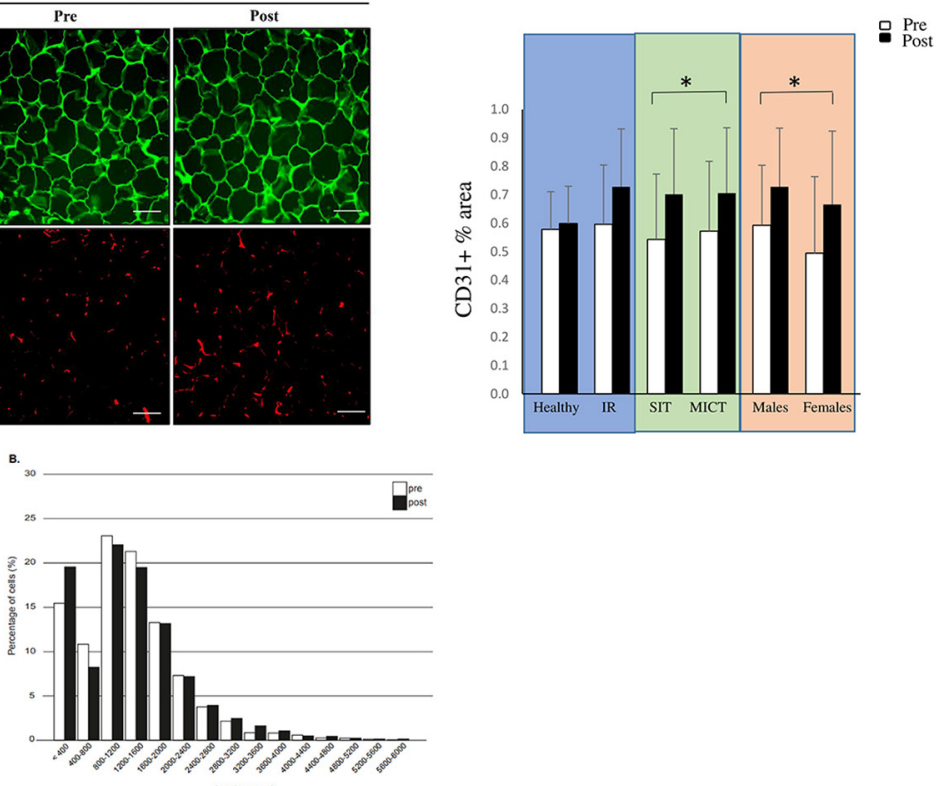

Figure 4 (A) Representative images of abdominal subcutaneous adipose tissue (SAT) stained with perilipin for adipocytes and CD31 for blood vessels. (B) Quantification of adipose tissue vasculature from CD31-stained sections. Values are shown in three different comparisons: healthy versus insulin-resistant (IR) men, sprint interval training (SIT) versus moderate-intensity continuous training (MICT) in IR participants and men versus women in IR participants. Data in the figure (B) are expressed as means and $95 \%$ Cls. ${ }^{*} p<0.05$, scale bar $100 \mathrm{~mm}$. (C) Adipocyte cell size distribution from the total population of cells in SAT in healthy $(A)$ and IR (B) participants before (white bars) and after (black bars) the intervention. Model-based means together with $95 \% \mathrm{Cls}$ are presented.

insulin-stimulated abdominal SAT glucose uptake rate but no change in VAT or femoral SAT glucose uptake after 11 weeks of endurance training $\left(>70 \% \mathrm{VO}_{2 \max }\right)$ in healthy sedentary moderately overweight men using PET and semiquantitative standard uptake modeling. ${ }^{34}$ The authors suggested that insulin sensitivity does not increase in non-contracting adipose tissue, similar to those skeletal muscles that are not active during exercise training. They also discussed about the possibility of contracting skeletal muscles signaling to adipose tissue to decrease glucose uptake to maintain the whole-body glucose homoeostasis. Interestingly, we found that when

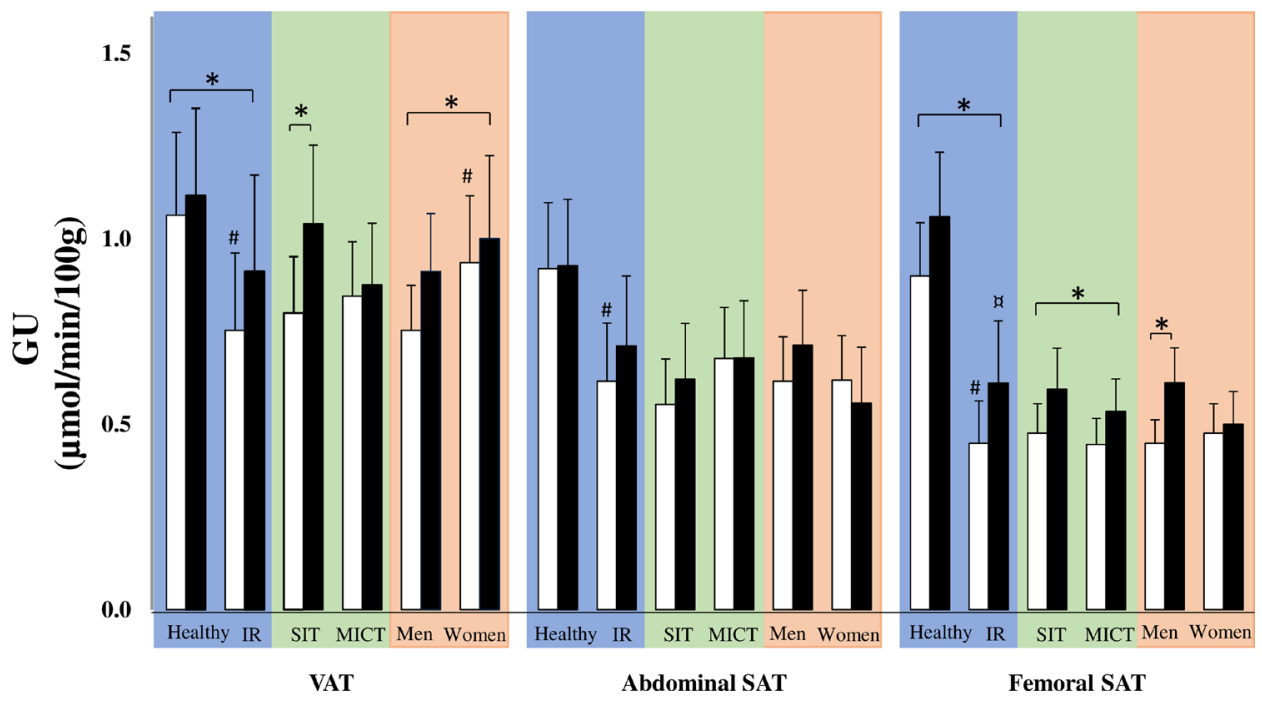

Figure 5 Insulin-stimulated glucose uptake (GU) per $100 \mathrm{~g}$ of tissue before (white bars) and after (black bars) the training intervention in visceral adipose tissue (VAT), abdominal subcutaneous adipose tissue (SAT) and femoral SAT. Glucose uptake is compared in three different comparisons: healthy versus insulin-resistant (IR) men (blue), sprint interval training (SIT) versus moderate-intensity continuous training (MICT) in IR participants (green) and men versus women in IR participants (red). All data are expressed as means and $95 \%$ Cls. $\# p<0.05$ : difference at baseline, ap $<0.0$ : baseline difference after training, ${ }^{*} p<0.05$ : the effect of exercise training over time in the whole group or a subgroup. Model-based means together with $95 \% \mathrm{Cls}$ are presented. 


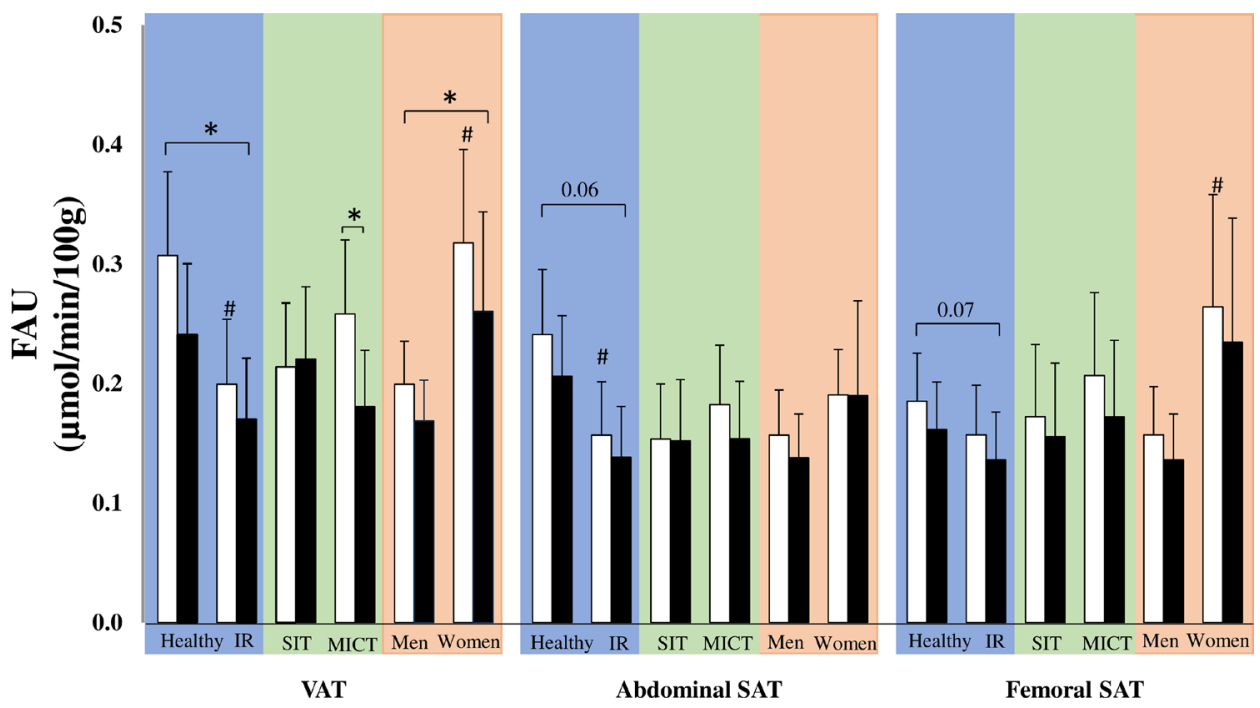

Figure 6 Fasting free fatty acid uptake (FAU) per $100 \mathrm{~g}$ of the tissue before (white bars) and after (black bars) the training intervention in visceral adipose tissue (VAT), abdominal subcutaneous adipose tissue (SAT) and femoral SAT. Glucose uptake is compared in three different comparisons: healthy versus insulin-resistant (IR) men (blue), sprint interval training (SIT) versus moderate-intensity continuous training (MICT) in IR participants (green) and men versus women in IR participants (red). All data are expressed as means and $95 \%$ Cls. $\# p<0.05$ : difference at baseline. ${ }^{*} p<0.05$ : the effect of exercise training over time in the whole group or a subgroup. Model-based means together with $95 \%$ Cls are presented.

using femoral muscle glucose uptake ${ }^{35}$ as a covariant, the increase in femoral SAT glucose uptake was no longer significant. This suggests that the observed improvement in femoral SAT glucose uptake is due to the enhancement of muscle glucose uptake facilitating the metabolism of nearby tissues. We also tested the improvement in VAT glucose uptake by taking the glucose uptake of the nearby muscles as a covariate and found no change in the result. However, VAT is not very closely associated with nearby muscles, as these muscles are not working as much as the thigh muscles during exercise. VAT has also been shown to be distinct from other white adipose tissues with higher cellularity and greater glucose uptake per adipocyte which may explain the finding. ${ }^{36}$

In humans, SAT insulin-stimulated glucose uptake has been shown to be higher in vitro and in vivo in trained compared with sedentary participants using microdialysis. ${ }^{37} 38$ Trained rats have also shown to have a greater relative amount of insulin-sensitive glucose transporters (GLUT4) as well as higher insulin-stimulated glucose transport in adipose tissue compared with sedentary animals. ${ }^{39-41}$ In the present study, we did not found
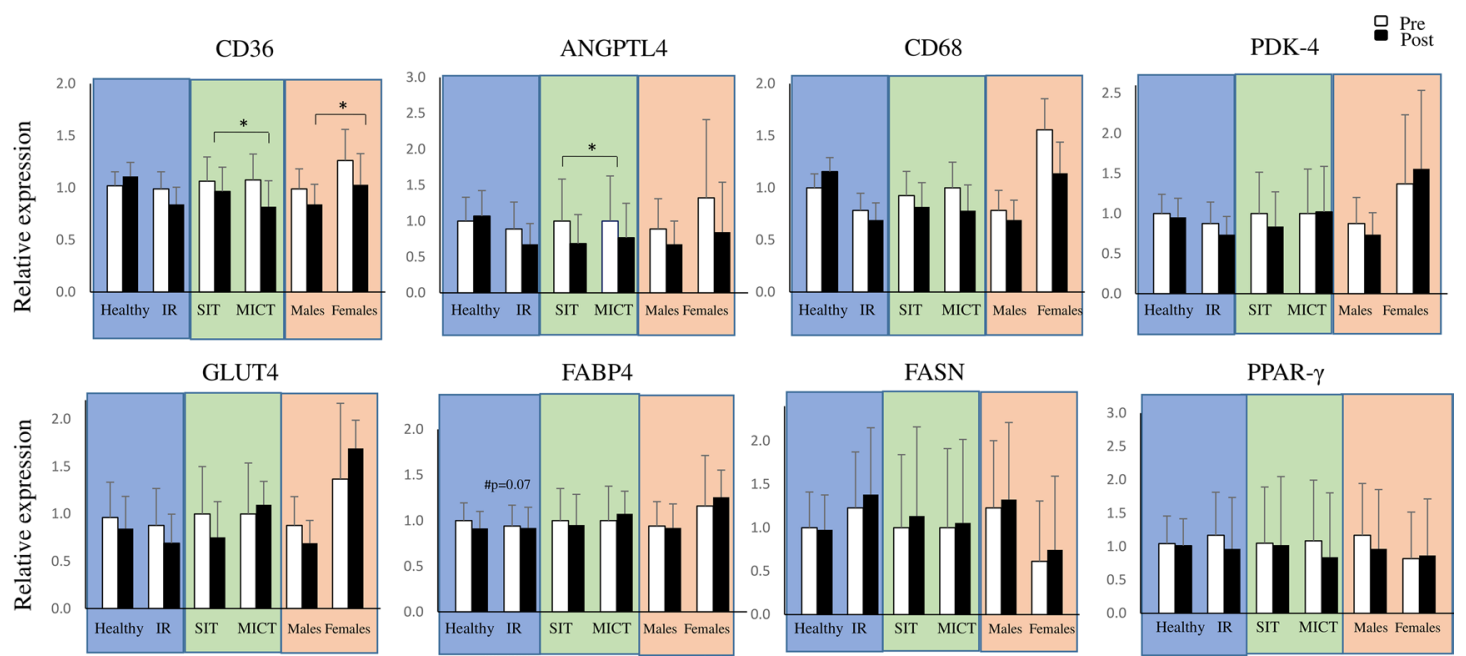

Figure 7 Gene expression of CD36, ANGPTL4, CD68, GLUT4, FABP4 and FASN in abdominal subcutaneous adipose tissue. Genes are visualized in three different comparisons: healthy versus insulin-resistant (IR) men, sprint interval training (SIT) versus moderate-intensity continuous training (MICT) in IR participants and men versus women in IR participants. All data are expressed as means and $95 \%$ Cls. ${ }^{*} p<0.05$ : the effect of exercise training over time in the whole group or a subgroup. ANGPTL4, angiopoietin-like 4; CD, cluster of differentiation; FABP4, fatty-acid binding protein 4; FASN, fatty acid synthase; GLUT4, glucose transporter type 4; PDK-4, pyruvate dehydrogenase lipoamide kinase isozyme 4; PPAR- $\gamma$, peroxisome proliferator-activated receptor gamma. Model-based means together with $95 \% \mathrm{Cls}$ are presented. 
any change in abdominal SAT GLUT-4 protein mRNA expression.

It has been previously shown that FABP4 and CD36 expression is upregulated in adipose tissue in participants with impaired insulin sensitivity and type 2 diabetes, associated with increased fatty acid uptake, adipocyte hypertrophy and inflammation. ${ }^{42-45}$ A previous FTHA-PET study conducted in our laboratory showed more than $100 \%$ higher fasting fatty acid uptake per $100 \mathrm{~g}$ in VAT, but not in abdominal SAT, in obese participants with a metabolic syndrome compared with lean participants. ${ }^{46}$ In the present study, we did not observe significant difference in FABP4 or CD36 mRNA expression in abdominal SAT between IR and healthy participants. In addition, we observed lower fasting fatty acid uptake in VAT and abdominal SAT in IR compared with healthy participants. Interestingly, although the IR group in the present study had significantly higher body adiposity and impaired whole-body insulin sensitivity, we observed no difference in fasting plasma FFA between the groups. At baseline we also found no differences between the groups in genes regulating fatty acid uptake FABP4, CD36 and ANGPTL4. Thus, currently we do not have an explanation as to why the baseline fatty acid uptake uptake was lower in the IR compared with the healthy group.

After training, fatty acid uptake decreased in VAT and tended to decrease in abdominal and femoral SAT in both groups. In SAT biopsies, we found a trend indicating a decreased expression of FABP4 in the IR but not in healthy participants (figure 7). In addition, when studying all IR participants, including women, both training modes led to a decrease in CD36 and ANGPTL4 mRNA expression in abdominal SAT (figure 7). Our results with ANGPTL4 are in agreement with another study where the expression of ANGPTL4 was reduced after 12 weeks of exercise intervention. ${ }^{47}$ Although there is growing amount of evidence that ANGPTL4 is a key player in angiogenesis, ${ }^{48}$ the mechanism of reduction in ANGPTL4 expression in adipose tissue in association with exercise training stays unknown. The more pronounced effect of training on VAT fatty acid uptake compared with abdominal and femoral fatty acid uptake could be explained by the notion of VAT being metabolically more active and having a higher expression of $\beta$-adrenergic receptors compared with SAT, and thus when stimulated by exercise training this leads to a higher lipolysis. ${ }^{49}$

Previous studies have shown a relationship between SAT adipocyte cell size and IR both in VAT and SAT. ${ }^{50} 51$ In addition, some studies have found an increased population of small adipocytes (diameter 20-50 $\mathrm{mm}$ ) in IR and type 2 diabetes. ${ }^{50253}$ It has been suggested that in an IR state the maturation of adipocytes into functional cells is impaired, which results in the accumulation of ectopic fat. ${ }^{545}$ In the present study, we did not find a baseline difference between the healthy and IR groups as regards the average or median abdominal SAT adipocyte cell size. However, IR participants showed a trend toward an increased fraction of small cells compared with the healthy participants both at baseline and after the exercise training (figure 4). After the training, we did not find a significant change in the mean or median adipocyte size in SAT, despite a small decrease in abdominal SAT mass. Thus, based on our present data and previous data collected by others, ${ }^{5657}$ it seems that longer training interventions and more prominent weight loss are needed to induce changes in adipocyte cell size. Importantly, we observed an increased vasculature in abdominal SAT and decreased VEGF-A levels in plasma, which indicate a better perfusion not only in adipose tissue but also at the whole-body level. This is important, since hypoxia is an important driver of the adipose tissue inflammation observed in obesity and type 2 diabetes. It has been suggested that the crosstalk between adipocytes and vascularization is often lost during adipose tissue expansion in obesity, leading to defective tissue perfusion, hypoxia and inflammation. ${ }^{58} 59$ Thus, our present findings indicate that exercise training can promote adipose tissue vascularization and homeostasis.

\section{SIT versus MICT (IR men and women)}

Several recent studies have shown that high-intensity training can induce improvement in cardiometabolic health indices that are comparable or superior to traditional moderate-intensity training despite the significantly shorter time commitment. ${ }^{60} 61$ However, no previous studies have compared the exercise training-induced responses in adipose tissue metabolism and morphology after SIT and MICT in IR participants.

Both SIT and MICT led to similar improvements in whole-body adiposity, insulin sensitivity and femoral SAT glucose uptake. Importantly, both training modes were associated with decreased VAT mass and decreased total and LDL cholesterol, which are known risk factors for cardiometabolic diseases. It is already well recognized that the reduction in VAT mass even independent of weight loss is associated with reduced cardiovascular disease risk. ${ }^{62}$ We observed significant improvement in VAT glucose uptake only after SIT and VAT fatty acid uptake only after MICT. During exercise, glycogen and lipids are the primary substrates oxidized in the mitochondria to support muscle contraction. The energy used during the lower intensity training is produced mainly from lipids that are hydrolyzed from triglycerides via lipolysis. ${ }^{63}$ Fat oxidation typically falls as exercise intensity increases from moderate to heavy, after which carbohydrate oxidation becomes primary source of the ATP. ${ }^{64}$ Therefore, during MICT, energy is mainly produced via fat oxidation, and during SIT via fast glycogen stores, which may explain the different response in VAT fatty acid uptake after SIT and MICT. ${ }^{7}$

\section{Women versus men}

It is well recognized that the fat accumulation in different depots differs between men and women. Men accumulate more VAT, whereas women accumulate more SAT and have a higher percentage of body fat compared with 
men. ${ }^{65}$ In the present study, the IR women had a $42 \%$ higher body fat content, a $51 \%$ higher abdominal SAT volume and a $45 \%$ lower VAT volume (online supplementary table 2) than the IR men. The women also had a significantly higher VAT glucose uptake (figure 5), VAT fatty acid uptake and femoral SAT fatty acid uptake compared with men. Our results are in line with previous animal and human studies and demonstrate that despite the higher level of total body fat, women are more insulin sensitive than men. ${ }^{20}$ These findings may be related to sex steroids, which are known to play a role in the regulation of adipose tissue development and function as well as whole-body insulin sensitivity, as it is considered that estrogen might have protective role against IR. ${ }^{20}$ Despite the significant baseline differences, the only difference between the males and females in the training response was observed in the femoral SAT glucose uptake, which only improved in men. This finding might be explained by higher muscle mass and pain tolerance in men, which allows men to push their limits further, especially during maximal effort in SIT training.

\section{Limitations}

The major limitation of our study is the relatively small number of participants, although it is in line with previous exercise training studies with similar technically and financially demanding and detailed designs. The statistical significance level was set to 0.05 , indicating that there is a $5 \%$ risk of finding a false positive result for a given variable. Given the large number of tests performed with a rather small number of subjects, it is possible that some of the findings of this paper may be false positive. Therefore, the results should be considered as hypothesis-generating explorative analysis.

The participants were instructed to maintain their normal eating habits during the study, but nutrition was not controlled. Thus, it might be that some of the study participants increased their food intake as their energy expenditure increased and some may have eaten healthier during the intervention. This could have blunted the effect of intervention for some outcomes.

\section{CONCLUSION}

In conclusion, the present study demonstrated that a 2-week short-term supervised, progressive exercise training intervention may improve adipose tissue metabolism both in healthy and IR participants independently of the sex. This study proposes that SIT improves VAT insulin-stimulated glucose uptake more efficiently than MICT, whereas MICT is preferable for VAT fatty acid uptake. Fatty acid uptake in adipose tissue and expression of FATB4, CD36 and ANGPTL4 mRNA decreases and adipose tissue vascularization increases in IR participants with training.

\footnotetext{
Author affiliations

${ }^{1}$ Turku PET Centre, University of Turku, Turku, Finland

${ }^{2}$ Stem Cells and Metabolism Research Program, Faculty of Medicine, University of Helsinki, Helsinki, Finland
}

${ }^{3}$ Department of Biostatistics, University of Turku, Turku, Finland ${ }^{4}$ Turku PET Centre, Turku University Hospital, Turku, Finland

Acknowledgements This study was conducted in the Finnish Centre of Excellence in Cardiovascular and Metabolic Research, supported by the Academy of Finland, University of Turku, Turku University Hospital and Åbo Akademi University. We thank all the volunteers who participated in the study and the staff of Turku PET Centre and the Paavo Nurmi Centre, especially exercise physiologist Jukka Kapanen (University of Turku, Paavo Nurmi Centre, Turku, Finland) and study nurse Mikko Koivumäki (University of Turku, Turku PET Centre, Turku, Finland). Kirsi Mattinen is acknowledged for her excellent help in biochemical analyses (University of Helsinki, Helsinki, Finland).

Contributors SMH and PM shared an equal authorship, analyzed and interpreted the data, and wrote the manuscript. RK, KAH and ET planned and performed biochemical analyses and interpreted the data; KKM and MAH analyzed the data and edited the manuscript. J-JE and KAV collected the data and edited the manuscript. EL contributed to statistical analysis and edited the manuscript. PN interpreted and edited the manuscript. KKK planned the experiments and edited the manuscript. JCH planned the experiments, interpreted the data and wrote the manuscript. JCH is the guarantor of this work and, as such, had full access to all the data in the study and takes responsibility for the integrity of the data and the accuracy of the data analysis.

Funding This study was financially supported by the European Foundation for the Study of Diabetes, the Hospital District of Southwest Finland, the Orion Research Foundation, the Finnish Diabetes Foundation, the Emil Aaltonen Foundation, the Academy of Finland (grants 251399, 251572, 256470, 281440, 283319 and 297245), the Ministry of Education of the State of Finland, the Paavo Nurmi Foundation, the Novo Nordisk, the Paulo Foundation, the Finnish Medical Foundation, the Turku University Foundation, the Finnish Cultural Foundation, Jenny and Antti Wihuri Foundation and Sigrid Juselius Foundation.

Competing interests None declared.

Patient consent for publication Not required.

Ethics approval The study was approved by the Ethical Committee of the Hospital District of Southwest Finland (Turku, Finland, decision 95/180/2010 §228) and was carried out according to the Declaration of Helsinki. All participants gave verbal and written informed consent.

Provenance and peer review Not commissioned; externally peer reviewed.

Data availability statement Data are available on request from the corresponding author (jhannukainen@gmail.com).

Open access This is an open access article distributed in accordance with the Creative Commons Attribution Non Commercial (CC BY-NC 4.0) license, which permits others to distribute, remix, adapt, build upon this work non-commercially, and license their derivative works on different terms, provided the original work is properly cited, appropriate credit is given, any changes made indicated, and the use is non-commercial. See: http://creativecommons.org/licenses/by-nc/4.0/.

ORCID iD

Jarna Christina Hannukainen http://orcid.org/0000-0002-8692-4049

\section{REFERENCES}

1 Wajchenberg BL. Subcutaneous and visceral adipose tissue: their relation to the metabolic syndrome. Endocr Rev 2000;21:697-738.

2 Longo M, Zatterale F, Naderi J, et al. Adipose tissue dysfunction as determinant of obesity-associated metabolic complications. Int $J$ Mol Sci 2019;20. doi:10.3390/ijms20092358. [Epub ahead of print: 13 May 2019].

3 Preis SR, Massaro JM, Robins SJ, et al. Abdominal subcutaneous and visceral adipose tissue and insulin resistance in the Framingham heart study. Obesity 2010;18:2191-8.

4 Després JP, Pouliot MC, Moorjani S, et al. Loss of abdominal fat and metabolic response to exercise training in obese women. Am J Physiol 1991;261:E159-67.

5 Schwartz RS, Shuman WP, Larson V, et al. The effect of intensive endurance exercise training on body fat distribution in young and older men. Metabolism 1991;40:545-51.

6 Lee S, Norheim F, Langleite TM, et al. Effects of long-term exercise on plasma adipokine levels and inflammation-related gene expression in subcutaneous adipose tissue in sedentary dysglycaemic, overweight men and sedentary normoglycaemic men of healthy weight. Diabetologia 2019;62:1048-64. 
7 Thompson D, Karpe F, Lafontan M, et al. Physical activity and exercise in the regulation of human adipose tissue physiology. Physiol Rev 2012;92:157-91.

8 Boström P, Wu J, Jedrychowski MP, et al. A PGC1- $\alpha$-dependent myokine that drives brown-fat-like development of white fat and thermogenesis. Nature 2012;481:463-8.

9 Stanford KI, Middelbeek RJW, Goodyear LJ. Erratum. Exercise Effects on White Adipose Tissue: Beiging and Metabolic Adaptations. Diabetes 2015;64:2361-2368. Diabetes 2015;64:3334.1-3334.

10 Trevellin E, Scorzeto M, Olivieri M, et al. Exercise training induces mitochondrial biogenesis and glucose uptake in subcutaneous adipose tissue through eNOS-dependent mechanisms. Diabetes 2014;63:2800-11.

11 Virtanen KA, Lönnroth P, Parkkola R, et al. Glucose uptake and perfusion in subcutaneous and visceral adipose tissue during insulin stimulation in nonobese and obese humans. J Clin Endocrinol Metab 2002;87:3902-10.

12 Hannukainen JC, Kalliokoski KK, Borra RJM, et al. Higher free fatty acid uptake in visceral than in abdominal subcutaneous fat tissue in men. Obesity 2010;18:261-5.

13 Bülow J, Madsen J. Adipose tissue blood flow during prolonged, heavy exercise. Pflugers Arch 1976;363:231-4.

14 Stallknecht B, Lorentsen J, Enevoldsen LH, et al. Role of the sympathoadrenergic system in adipose tissue metabolism during exercise in humans. J Physiol 2001;536:283-94.

15 Romijn JA, Coyle EF, Sidossis LS, et al. Regulation of endogenous fat and carbohydrate metabolism in relation to exercise intensity and duration. Am J Physiol 1993;265:E380-91.

16 Burgomaster KA, Hughes SC, Heigenhauser GJF, et al. Six sessions of sprint interval training increases muscle oxidative potential and cycle endurance capacity in humans. J Appl Physiol 2005;98:1985-90.

17 Little JP, Gillen JB, Percival ME, et al. Low-Volume high-intensity interval training reduces hyperglycemia and increases muscle mitochondrial capacity in patients with type 2 diabetes. J App Physiol 2011;111:1554-60.

18 Gibala MJ, Little JP. Just hit it! a time-efficient exercise strategy to improve muscle insulin sensitivity. J Physiol 2010;588:3341-2.

19 Little JP, Safdar A, Wilkin GP, et al. A practical model of low-volume high-intensity interval training induces mitochondrial biogenesis in human skeletal muscle: potential mechanisms. J Physiol 2010;588:1011-22.

20 Macotela Y, Boucher J, Tran TT, et al. Sex and depot differences in adipocyte insulin sensitivity and glucose metabolism. Diabetes 2009;58:803-12

21 Honkala SM, Motiani KK, Eskelinen J-J, et al. Exercise training reduces intrathoracic fat regardless of defective glucose tolerance. Med Sci Sports Exerc 2017;49:1313-22.

22 Eskelinen J-J, Heinonen I, Löyttyniemi E, et al. Muscle-Specific glucose and free fatty acid uptake after sprint interval and moderateintensity training in healthy middle-aged men. J Appl Physiol 2015;118:1172-80.

23 Heiskanen MA, Motiani KK, Mari A, et al. Exercise training decreases pancreatic fat content and improves beta cell function regardless of baseline glucose tolerance: a randomised controlled trial. Diabetologia 2018;61:1817-28.

24 Motiani KK, Savolainen AM, Toivanen J, et al. Effects of short-term sprint interval and moderate-intensity continuous training on liver fat content, lipoprotein profile, and substrate uptake: a randomized trial. J Appl Physiol 2019;126:1756-68.

25 American Diabetes Association. 2. classification and diagnosis of diabetes. Diabetes Care 2017;40:S11-24.

26 Kiviniemi AM, Tulppo MP, Eskelinen JJ, et al. Cardiac autonomic function and high-intensity interval training in middle-age men. Med Sci Sports Exerc 2014;46:1960-7.

27 Eskelinen J-J, Heinonen I, Löyttyniemi E, et al. Left ventricular vascular and metabolic adaptations to high-intensity interval and moderate intensity continuous training: a randomized trial in healthy middle-aged men. J Physiol 2016;594:7127-40.

28 Heiskanen MA, Leskinen T, Heinonen IHA, et al. Right ventricular metabolic adaptations to high-intensity interval and moderateintensity continuous training in healthy middle-aged men. $\mathrm{Am} \mathrm{J}$ Physiol Heart Circ Physiol 2016;311:H667-75.

29 Sjöros TJ, Heiskanen MA, Motiani KK, et al. Increased insulinstimulated glucose uptake in both leg and arm muscles after sprint interval and moderate-intensity training in subjects with type 2 diabetes or prediabetes. Scand J Med Sci Sports 2018;28:77-87.

30 DeFronzo RA, Tobin JD, Andres R. Glucose clamp technique: a method for quantifying insulin secretion and resistance. Am J Physiol 1979;237:E214-23.
31 Nuutila P, Peltoniemi P, Oikonen V, et al. Enhanced stimulation of glucose uptake by insulin increases exercise-stimulated glucose uptake in skeletal muscle in humans: studies using [15O]O2, [15O] $\mathrm{H} 2 \mathrm{O}$, [18F]fluoro-deoxy-glucose, and positron emission tomography. Diabetes 2000;49:1084-91.

32 Carpenter AE, Jones TR, Lamprecht MR, et al. CellProfiler: image analysis software for identifying and quantifying cell phenotypes. Genome Biol 2006; 7:R100.

33 Kiviniemi AM, Tulppo MP, Eskelinen JJ, et al. Autonomic function predicts fitness response to short-term high-intensity interval training. Int J Sports Med 2015;36:915-21.

34 Reichkendler $\mathrm{MH}$, Auerbach $\mathrm{P}$, Rosenkilde M, et al. Exercise training favors increased insulin-stimulated glucose uptake in skeletal muscle in contrast to adipose tissue: a randomized study using FDG PET imaging. Am J Physiol Endocrinol Metab 2013;305:E496-506.

35 Sjöros TJ, Heiskanen MA, Motiani KK, et al. Increased insulinstimulated glucose uptake in both leg and arm muscles after sprint interval and moderate-intensity training in subjects with type 2 diabetes or prediabetes. Scand J Med Sci Sports 2018;28:77-87.

36 Bjørndal B, Burri L, Staalesen V, et al. Different adipose depots: their role in the development of metabolic syndrome and mitochondrial response to hypolipidemic agents. J Obes 2011;2011:1-15.

37 Rodnick KJ, Haskell WL, Swislocki AL, et al. Improved insulin action in muscle, liver, and adipose tissue in physically trained human subjects. Am J Physiol 1987;253:E489-95.

38 Stallknecht B, Larsen JJ, Mikines KJ, et al. Effect of training on insulin sensitivity of glucose uptake and lipolysis in human adipose tissue. Am J Physiol Endocrinol Metab 2000;279:E376-85.

39 Craig BW, Hammons GT, Garthwaite SM, et al. Adaptation of fat cells to exercise: response of glucose uptake and oxidation to insulin. J Appl Physiol Respir Environ Exerc Physiol 1981;51:1500-6.

40 James DE, Kraegen EW, Chisholm DJ. Effects of exercise training on in vivo insulin action in individual tissues of the rat. $J$ Clin Invest 1985;76:657-66.

41 Stallknecht B, Andersen PH, Vinten J, et al. Effect of physical training on glucose transporter protein and mRNA levels in rat adipocytes. Am J Physiol 1993;265:E128-34.

$42 \mathrm{Kahn}$ BB. Alterations in glucose transporter expression and function in diabetes: mechanisms for insulin resistance. J Cell Biochem 1992;48:122-8

43 Rondinone CM, Wang L-M, Lonnroth $\mathrm{P}$, et al. Insulin receptor substrate (IRS) 1 is reduced and IRS-2 is the main docking protein for phosphatidylinositol 3-kinase in adipocytes from subjects with non-insulin-dependent diabetes mellitus. Proc Natl Acad Sci U S A 1997;94:4171-5

44 Bonen A, Tandon NN, Glatz JFC, et al. The fatty acid transporter FAT/CD36 is upregulated in subcutaneous and visceral adipose tissues in human obesity and type 2 diabetes. Int $J$ Obes 2006:30:877-83.

45 Dadson P, Ferrannini E, Landini L, et al. Fatty acid uptake and blood flow in adipose tissue compartments of morbidly obese subjects with or without type 2 diabetes: effects of bariatric surgery. Am J Physiol Endocrinol Metab 2017;313:E175-82.

46 Bucci M, Karmi AC, lozzo P, et al. Enhanced fatty acid uptake in visceral adipose tissue is not reversed by weight loss in obese individuals with the metabolic syndrome. Diabetologia 2015;58:158-64.

47 Cullberg KB, Christiansen T, Paulsen SK, et al. Effect of weight loss and exercise on angiogenic factors in the circulation and in adipose tissue in obese subjects. Obesity 2013;21:454-60.

48 Galaup A, Cazes A, Le Jan S, et al. Angiopoietin-Like 4 prevents metastasis through inhibition of vascular permeability and tumor cell motility and invasiveness. Proc Natl Acad Sci U S A 2006;103:18721-6.

49 Tsiloulis T, Watt MJ. Exercise and the Regulation of Adipose Tissue Metabolism. In: Progress in molecular biology and translational science. In, 2015: p175-201. http://www.ncbi.nlm.nih.gov/pubmed/ 26477915

50 Weyer C, Foley JE, Bogardus C, et al. Enlarged subcutaneous abdominal adipocyte size, but not obesity itself, predicts type II diabetes independent of insulin resistance. Diabetologia 2000;43:1498-506.

51 Laforest S, Labrecque J, Michaud A, et al. Adipocyte size as a determinant of metabolic disease and adipose tissue dysfunction. Crit Rev Clin Lab Sci 2015;52:301-13.

52 Lönn M, Mehlig K, Bengtsson C, et al. Adipocyte size predicts incidence of type 2 diabetes in women. Faseb J 2010;24:326-31.

53 McLaughlin T, Sherman A, Tsao P, et al. Enhanced proportion of small adipose cells in insulin-resistant vs insulin-sensitive obese individuals implicates impaired adipogenesis. Diabetologia 2007;50:1707-15. 
54 DeFronzo RA. Dysfunctional fat cells, lipotoxicity and type 2 diabetes. Int J Clin Pract Suppl 2004;143:9-21.

55 Salans LB, Dougherty JW. The effect of insulin upon glucose metabolism by adipose cells of different size. J Clin Invest 1971;50:1399-410.

56 Stinkens R, Brouwers B, Jocken JW, et al. Exercise traininginduced effects on the abdominal subcutaneous adipose tissue phenotype in humans with obesity. J Appl Physiol 2018;125:1585-93.

57 Després JP, Bouchard C, Savard R, et al. The effect of a 20-week endurance training program on adipose-tissue morphology and lipolysis in men and women. Metabolism 1984;33:235-9.

58 Hosogai N, Fukuhara A, Oshima K, et al. Adipose tissue hypoxia in obesity and its impact on adipocytokine dysregulation. Diabetes 2007;56:901-11.

59 Gregor MF, Hotamisligil GS. Thematic review series: adipocyte biology. adipocyte stress: the endoplasmic reticulum and metabolic disease. J Lipid Res 2007;48:1905-14.
60 Gibala MJ, Little JP, van Essen M, et al. Short-term sprint interval versus traditional endurance training: similar initial adaptations in human skeletal muscle and exercise performance. J Physiol 2006;575:901-11.

61 Gillen JB, Gibala MJ. Is high-intensity interval training a time-efficient exercise strategy to improve health and fitness? Appl Physiol Nutr Metab 2014;39:409-12.

62 Goedecke JH, Micklesfield LK. The Effect of Exercise on Obesity, Body Fat Distribution and Risk for Type 2 Diabetes. In: Medicine and sport science. In, 2014: p82-93. http://www.ncbi.nlm.nih.gov/ pubmed/25226803

63 Coyle EF. Substrate utilization during exercise in active people. Am J Clin Nutr 1995;61:968S-79.

64 Frayn KN. Macronutrient metabolism of adipose tissue at rest and during exercise: a methodological viewpoint. Proc Nutr Soc 1999;58:877-86.

65 Kissebah AH, Krakower GR. Regional adiposity and morbidity. Physiol Rev 1994;74:761-811. 